\title{
FORAMINIFERAL TURNOVER IN NERITIC ENVIRONMENTS IN THE OLIGOCENE OF SOUTHERN AUSTRALIA
}

MOSS*, Graham D., Department of Geology and Geophysics, University of Adelaide, GPO Box 498, Adelaide, South Australia 5001

This study explores an excellent mid-latitude Oligocene calcareous neritic succession that spans the Eocene/Oligocene boundary to the Miocene. Rapid changes in sea level and climate should have a palpable influence on macroevolution and the Eocene-Oligocene transition marks one of the most substantial changes for the Cainozoic.

Stratigraphic ranges of some 130 benthic and 20 planktic species occurring in two contrasting marine environments, one relatively restricted (low plankton - Murray Basin) and another more open (high plankton - Otway Basin) to oceanic processes, were identified and correlated with signals derived from changes in the physical environment. The signals include: the 'Exxon' sea-level curve, deep sea stable isotope curves, and prominent lithological changes.

There is a significant turnover of species at the Eocene/Oligocene boundary. This event impacts on all assemblages and correlation metrics indicate that there is an 'across-the-board' response. Interestingly, the turnover corresponds to a local Saint Vincent Basin lithological change from the grey-green, organic rich facies of the Blanche Point Formation to the red-yellow-brown, well oxidized, quartz and bryozoa rich facies of the Port Willunga Formation. This switch is in turn coincident with the saltatory positive deviation in the $\delta^{18} \mathrm{O}$ top and bottom water curves derived from oceanic sections.

The turnover pattern is not repeated at the major sea level fall predicted for the mid Oligocene (at 30 million years), neither is there any comparable lithological transition. Geographically widespread species (common to all environments) cross this supposed prominent type one sequence boundary, there is a signal but the impact on the fauna is less than that detected for the Eocene/Oligocene boundary. Those faunas that were more restricted to open ocean processes exhibited shorter stratigraphic ranges and appeared to be controlled primarily by sea level fluctuation and salinity changes. There is evidence to suggest that foraminiferal faunas of the more restricted environment in southern Australia were less responsive to the well mixed, thermohaline driven ocean of the Oligocene. Generally, Oligocene benthic assemblages are dominated by Cibicides, Notorotalia and Buliminid species in consistently high numbers, indicating a high dominance of relatively few taxa, that is, large populations and low diversity. Faunas of open ocean assemblages demonstrate relatively subdued turnover patterns compared to those of more restricted environments.

The Late Eocene displays parallel patterns of foraminiferal turnover and the Oligocene is characterised by inter-basin contrasts. In comparison to the Eocene, faunas appear to be more robust in the psychrosphere constrained ocean of the Oligocene. It is proposed that these patterns indicate that the Latest Eocene was dominated by species adapted to a specialist life strategy while the Oligocene reflect patterns more often associated with opportunist colonization. 